\title{
Yield-determining factors in high-solids enzymatic hydrolysis of
} lignocellulose

\author{
Jan B Kristensen ${ }^{1,2}$, Claus Felby ${ }^{1}$ and Henning Jørgensen*1
}

Address: ${ }^{1}$ Forest and Landscape Denmark, University of Copenhagen, Rolighedsvej 23, DK-1958 Frederiksberg, Denmark and ${ }^{2}$ Novozymes A/S, Krogshøjvej 36, DK-2880 Bagsværd, Denmark

Email: Jan B Kristensen - JBhK@novozymes.com; Claus Felby - cf@life.ku.dk; Henning Jørgensen* - hnj@life.ku.dk

* Corresponding author

Published: 8 June 2009

Biotechnology for Biofuels 2009, 2:1 I doi:10.1 186/1754-6834-2-II

This article is available from: http://www.biotechnologyforbiofuels.com/content/2/I/II

(c) 2009 Kristensen et al.; licensee BioMed Central Ltd.

This is an open access article distributed under the terms of the Creative Commons Attribution License (http://creativecommons.org/licenses/by/2.0), which permits unrestricted use, distribution, and reproduction in any medium, provided the original work is properly cited.
Received: 12 November 2008

Accepted: 8 June 2009

\begin{abstract}
Background: Working at high solids (substrate) concentrations is advantageous in enzymatic conversion of lignocellulosic biomass as it increases product concentrations and plant productivity while lowering energy and water input. However, for a number of lignocellulosic substrates it has been shown that at increasing substrate concentration, the corresponding yield decreases in a fashion which can not be explained by current models and knowledge of enzyme-substrate interactions. This decrease in yield is undesirable as it offsets the advantages of working at high solids levels. The cause of the 'solids effect' has so far remained unknown.

Results: The decreasing conversion at increasing solids concentrations was found to be a generic or intrinsic effect, describing a linear correlation from 5 to $30 \%$ initial total solids content $(\mathrm{w} / \mathrm{w})$. Insufficient mixing has previously been shown not to be involved in the effect. Hydrolysis experiments with filter paper showed that neither lignin content nor hemicellulose-derived inhibitors appear to be responsible for the decrease in yields. Product inhibition by glucose and in particular cellobiose (and ethanol in simultaneous saccharification and fermentation) at the increased concentrations at high solids loading plays a role but could not completely account for the decreasing conversion. Adsorption of cellulases was found to decrease at increasing solids concentrations. There was a strong correlation between the decreasing adsorption and conversion, indicating that the inhibition of cellulase adsorption to cellulose is causing the decrease in yield.
\end{abstract}

Conclusion: Inhibition of enzyme adsorption by hydrolysis products appear to be the main cause of the decreasing yields at increasing substrate concentrations in the enzymatic decomposition of cellulosic biomass. In order to facilitate high conversions at high solids concentrations, understanding of the mechanisms involved in high-solids product inhibition and adsorption inhibition must be improved.

\section{Background}

Climate changes and shortage of fossil fuels have sparked a growing demand for liquid biofuels which in turn has increased the amount of research into the production of lignocellulose-derived bioethanol [1,2]. However, being an insoluble and highly heterogeneous substrate, lignocellulosic materials pose several challenges in conversion to fermentable sugars. In addition to understanding com- 
plex enzyme system kinetics, these biomass-related challenges include recalcitrance to hydrolysis [3] and mixing difficulties [4]. Water content in the hydrolysis slurry is directly correlated to rheology, that is, viscosity and shear rate during mixing [5], important for the interaction between lignocellulose and cell wall-degrading enzymes. Thus, water is not only critical in hydrolysis being a substrate and a prerequisite for enzyme function, but is also crucial for enzyme transport mechanisms throughout hydrolysis as well as mass transfer of intermediates and end-products [6]. Maintaining high substrate concentrations throughout the conversion process from biomass to ethanol is important for the energy balance and economic viability of bioethanol production.

High-solids enzymatic hydrolysis can be defined as taking place at solids levels where initially there are no significant amounts of free liquid water present [7]. By increasing the solids loading, the resulting sugar concentration and consequently ethanol concentration increase, having significant effects on processing costs, in particular distillation [8-10]. Furthermore, lower water content allows for a larger system capacity, less energy for heating and cooling of the slurry and less waste water [4]. Model-based estimations have shown significant reductions of operating costs of simultaneous saccharification and fermentation (SSF) of pretreated softwood when the initial solids concentration was increased [8]. Unfortunately, there are also disadvantages to increasing the substrate concentration. Concentrations of end products and inhibitors will increase, causing enzymes and fermenting organisms to not function optimally. Also, high-solids loadings can cause insufficient mixing, or mixing can be too energyconsuming in conventional stirred-tank reactors as the viscosity of slurries increases abruptly at increasing solids loadings, in particular over $20 \%$ solids $[11,12]$.

In situ native cellulase systems have been reported to function at solids levels as high as $76 \%$ (all concentrations are given as total solids on a $w / w$ basis) [13], indicating that enzymatic hydrolysis may be limited by the laboratory or industrial process set-up. Twelve to fifteen per cent total solids is often considered the upper limit at which pretreated biomass can be mixed and hydrolysed in conventional stirred-tank reactors $[7,14,15]$. However, at the laboratory scale, enzymatic hydrolysis at up to $32 \%$ total solids has been reported $[12,16]$. A number of studies have utilised fed-batch operations in order to increase the final solids loading $[7,11,17,18]$. We have previously described a gravimetric mixing reactor design that allows batch enzymatic liquefaction and hydrolysis of pretreated wheat straw at up to $40 \%$ solids concentration [4]. This is a significant increase from what has previously been possible, and thus significantly increases the techno-economic potential of the whole process. The gravimetric mixing principle has been up-scaled and used in a pilot plant for several years $[19,20]$.

During the work with high solids concentrations we found that the enzymatic conversion (percent of theoretical) linearly decreased with increasing solids concentration (constant enzyme to substrate ratio) [4]. This decrease partly offsets the advantages of running at high solids concentrations. As seen in Figure 1, the effect has been observed in both enzymatic hydrolysis and SSF by several groups working with various kinds of biomass $[12,16-18,21-24]$. Although several of these studies were conducted at less than $10 \%$ initial solids content, the phenomenon appears to be an intrinsic or generic effect of enzymatic hydrolysis at increasing solids levels. In this paper, the decrease in yield at high solids concentrations is referred to as the solids effect.

Some groups have suggested that the mechanism behind the decreasing conversion is product inhibition $[12,16,25]$ or inhibition by other compounds such as sugar-derived inhibitors (furfural and hydroxymethylfurfural (HMF)) [26] and lignin [27]. Others have suggested it may be explained by mass transfer limitations or other effects related to the increased content of insoluble solids, such as non-productive adsorption of enzymes [14,28].

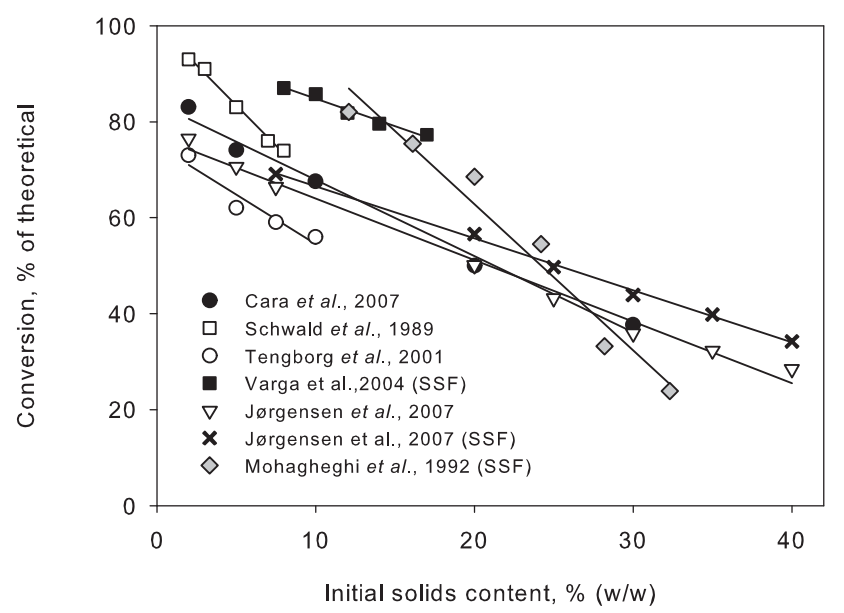

\section{Figure I}

Decreasing conversion of biomass. Results collected from several publications indicate that decreasing conversion at increasing solids content is a general effect. Results are for different kinds of biomass and for both enzymatic hydrolysis and simultaneous saccharification and fermentation (SSF). Added trend lines show that for each experiment there is a linear relationships between initial solids content and yield. Data taken from [24] (enzymatic hydrolysis), [16] (enzymatic hydrolysis), [23] (enzymatic hydrolysis), [I7] (SSF), [4] (enzymatic hydrolysis and SSF) and [12] (SSF). 
However, the specific mechanism(s) responsible for the decreasing hydrolytic efficiency are still uncertain $[4,29]$.

It should be noted that inhibition primarily affects the hydrolysis rate and not the maximum conversion or yield, given sufficient time. With limited reaction times and not fully converted, the conversion will correspond to the inhibition, that is, the conversion being a measure of the 'accumulated' inhibition. Working with initial reaction velocities in high-solids hydrolysis involves great difficulties due to the non-liquid properties of the substrate. For that reason, degree of conversion has been used to estimate the increased inhibition that appears to take place at elevated solids contents.

In this paper the possible mechanisms behind the solids effect have been divided into the following four categories: Compositional and substrate effects; product inhibition; water concentration; and cellulase adsorption. These four topics will be introduced below.

\section{Compositional and substrate effects}

The heterogeneity and structure of lignocellulosic biomass means that high viscosity prevents efficient mixing at high solids concentrations when performed in conventional stirred-tank reactors $[14,28,30]$. The viscosity of lignocellulosic slurries increases sharply over a certain threshold (typically around $20 \%$ solids) but, despite the extreme difference in viscosity between, for example, 5\% and $40 \%$ solids loading, the conversion of lignocellulosics as a function of solids appears to be linear (Figure 1). Although mixing of substrate and enzymes is crucial for an efficient liquefaction, our previous findings showed that it does not appear that lack of mixing is the cause of the decreasing conversion, at least not at the solids levels documented [4]. This is in accordance with the recent findings of Hodge and co-workers who concluded that possible mass transfer limitations caused by insoluble solids were not apparent at below $20 \%$ insoluble solids content [25]. At very high solids levels (above 20 to 30\% dry matter), a mass transfer limitation may be involved in the lower yield, but the linearity of the solids effect over a large range of conditions with a number of substrates (wheat and barley straw $[4,12,14]$, corn stover [17], softwood $[22,24]$, hardwood $[16,23]$ and an industrial ethanol fermentation residue (vinasse) [28]) indicates that a single factor may be responsible for the effect (all the way from, for example, $5 \%$ to $40 \%$ dry matter).

In order to be able to establish that the solids effect is not caused by lignin adsorption or lignin-derived inhibitors (phenolics), experiments for this paper were carried out with filter paper. Filter paper has the advantage of containing no lignin yet still retains the secondary cell wall structure, as opposed to Sigmacell and Avicel, for example.

\section{Product inhibition}

End-product inhibition plays an important role in enzymatic hydrolysis as glucose, cellobiose and ethanol have demonstrated their ability to significantly inhibit endoglucanases, cellobiohydrolases and $\beta$-glucosidase $[31,32]$. However, working with an insoluble substrate and kinetics that do not follow the Michaelis-Menten model, the exact type of inhibition is difficult to determine [33]. The decrease in hydrolysis rate over time has been attributed to inhibition by the accumulated end products [34]. Others conclude that when hydrolysing natural, lignocellulosic substrates, cellulases are more resistant to product inhibition than with amorphous reference materials and that the early stage decrease in hydrolysis rate is not caused by product inhibition [35,36]. In high-solids enzymatic hydrolysis of pretreated corn stover, Hodge and coworkers recently found that increased sugar concentrations were the primary cause of performance inhibition [25]. Based on the above, we have investigated the inhibitory effect of increased sugar concentration in connection with high-solids enzymatic hydrolysis.

\section{Water concentration}

Working with a system with low water content may directly affect enzyme performance. Not only is water a substrate for the hydrolysis but it is also the solvent that allows the function of enzymes, contact between enzymes and substrate and transport of products [37]. We have previously investigated the role of water in enzymatic hydrolysis [6]. In this study, we wanted to investigate if the solids effect was related to a lower concentration of water in relation to solids. As mentioned, hydrolysis is possible at very high solids concentrations but the rate of reaction may be impaired under such conditions [13].

We have investigated the role of water concentration by replacing various amounts of the water in enzymatic hydrolysis with oleyl alcohol, an inert oil that does not directly affect the function of the enzymes $[38,39]$.

\section{Cellulase adsorption}

Cellulose accessibility and degree of adsorption of cellulases are well known as controlling factors for conversion rates and yields $[40,41]$. It has long been known that certain hydrolysis products are able to inhibit cellulase adsorption [42]. It has, however, recently been shown that glucose and especially cellobiose strongly inhibit cellulase adsorption in a linear fashion [43]. This adsorption inhibition can be seen as a sub-class of product inhibition where the catalytic site may not necessarily be involved. In order to investigate whether adsorption (or lack thereof) could possibly be involved in the observed solids effect, 
the adsorption of enzyme was measured in hydrolysis of filter paper at different solids contents.

\section{Results and discussion Compositional and substrate effects}

Filter paper was used as a model substrate. As seen in Figure $2 \mathrm{~A}$, filter paper hydrolysis displayed the characteristic profiles, with a very high initial rate of conversion that decreases considerably after only 6 to $8 \mathrm{~h}$. When the conversion was displayed as a function of initial solids content, the characteristic downward curve was observed (Figure 2B). Again, the relationship is linear with a decrease from $56.5 \%$ conversion at $5 \%$ initial solids con-
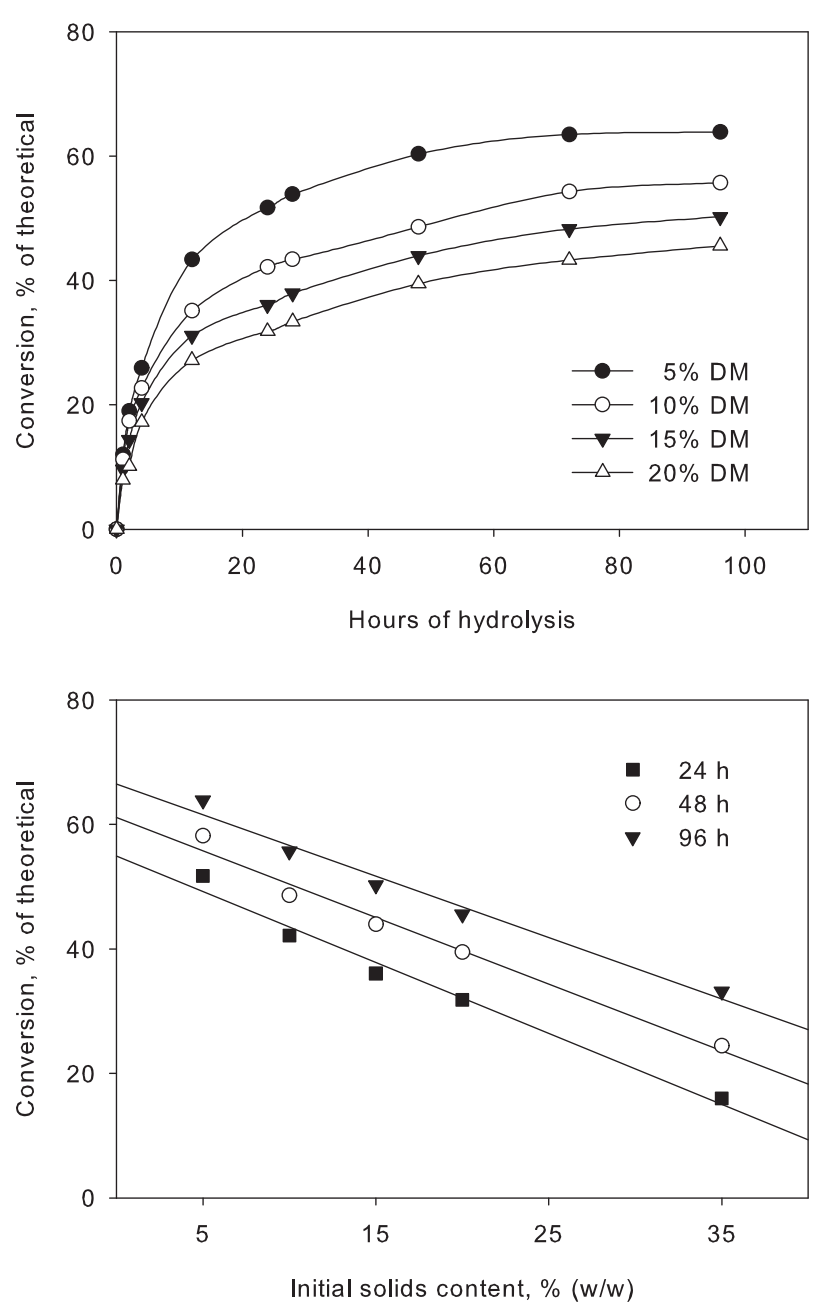

Figure 2

Hydrolysis of filter paper. Hydrolysis of filter paper at large laboratory scale with 5, 10, I5, 20 and $35 \%$ initial solids content $(w / w)$ and an enzyme dosage of 10 FPU per gram dry matter (DM). A: Hydrolysis profiles for 5, 10, 15 and 20\% DM as a function of time. B: Cellulose conversion as a function of initial solids concentration. tent to $22.8 \%$ conversion at $25 \%$ initial solids content, both after $24 \mathrm{~h}$ of hydrolysis at large laboratory scale (see explanation of 'small' and 'large' laboratory scale in the Methods section). The 5\% solids conversions shown in Figure $2 \mathrm{~B}$ are slightly higher than the linear curve. This observation is not in accordance with previous results of hydrolysis at different scales and is possibly a measurement artefact $[4,44]$. Numerous other experiments have been performed with filter paper (not shown). As above, they all exhibited the same solids effect as observed with a range of lignocellulosic substrates with varying lignin content. Based on this it is unlikely that lignin or other phenolics are responsible for the solids effect.

The filter paper used in the experiments for the present paper contained approximately $15 \%$ hemicellulose in the form of $14 \%$ mannan and $1 \%$ arabinan. However, experiments with hydrolysis of Whatman filter paper (98\% cellulose) (not shown) and hydrolysis of $\alpha$-cellulose also displayed the same trend at increasing solids loadings [21]. As regarding lignin, the fact that a hemicellulose-free substrate exhibits the same trend at increasing solids contents indicates that hemicellulose-derived sugars/inhibitors are not the cause of the solids effect either.

\section{Product inhibition}

To investigate the role of product inhibition in high-solids enzymatic hydrolysis, various amounts of sugar were added to a hydrolysis of filter paper. An example of such an experiment (at large laboratory scale) is seen in Figure 3 . With $50 \mathrm{~g} / \mathrm{l}$ glucose added, the rate of hydrolysis during the first few hours was significantly reduced compared with the reference, in particular for the 5\% solids hydrolysis where the initial phase of fast conversion was completely absent. As there is a constant enzyme dosage per gram of solids in the experiments, the ratio between glucose and enzyme is much higher at $5 \%$ than $20 \%$ solids (for the hydrolyses with $50 \mathrm{~g} / \mathrm{l}$ glucose added) and the stronger inhibition is thus not surprising. Although $4 \mathrm{~h}$ makes up a small part of the whole hydrolysis time, the fast rate of hydrolysis in the first phase is responsible for conversion of a major part of the substrate. Interestingly, after approximately $4 \mathrm{~h}$, the rate of hydrolysis at $20 \%$ is nearly identical despite the difference in glucose level. This indicates that one of two things is happening. Either there are other and stronger factors inhibiting the hydrolysis after the first phase, thereby 'masking' the product inhibition, or there is a certain glucose level threshold, above which the enzymes are inhibited to a similar extent and thus resulting in a similar hydrolysis rate.

It is worth noting that it is not only the concentration of the inhibitor that is important but the inhibitor-toenzyme ratio should also be considered. Depending on the difference in concentrations of substrate and enzymes 


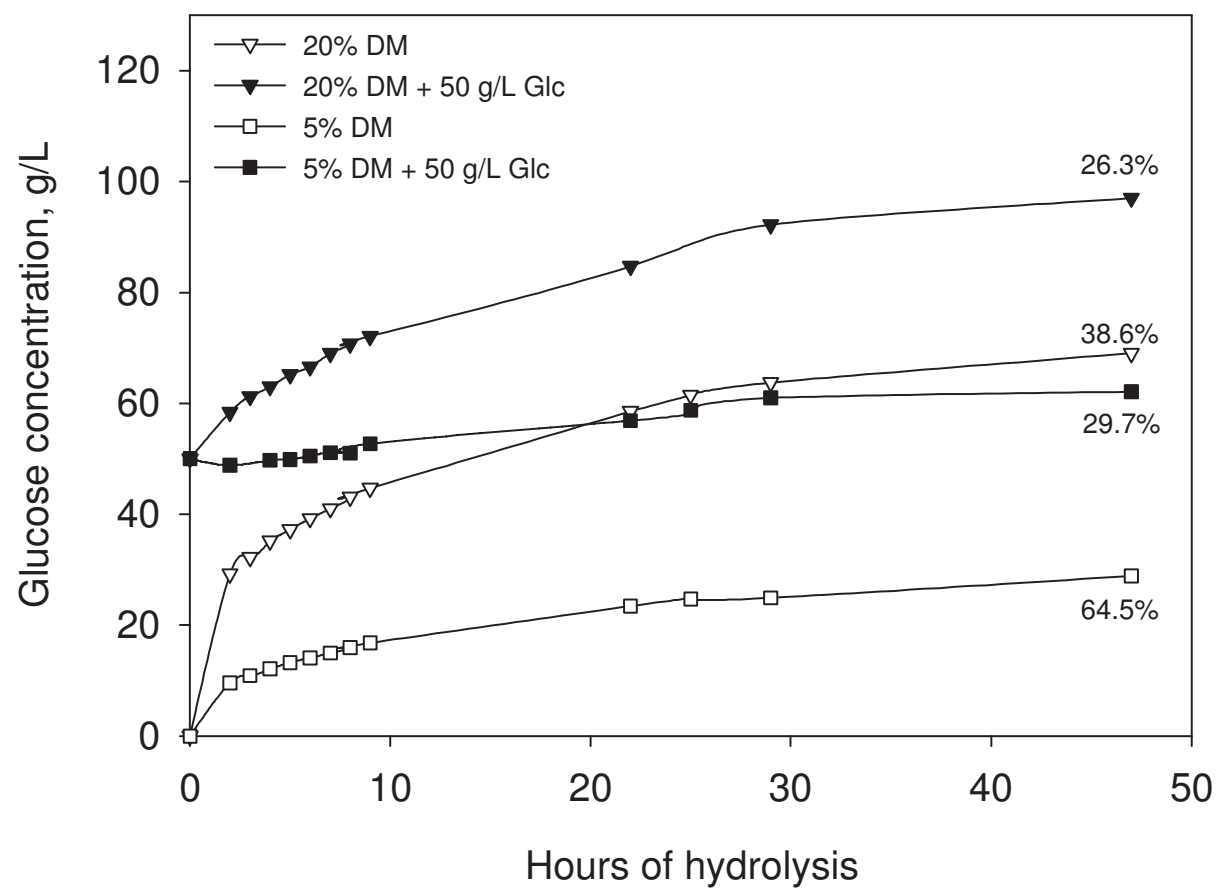

\section{Figure 3}

Hydrolysis of filter paper. Hydrolysis of filter paper at large laboratory scale with $5 \%$ (punctuated line) and $20 \%$ (solid line) initial solids content (w/w) and an enzyme dosage of 10 FPU per gram dry matter (DM). Before addition of enzyme, 50 g/l glucose was added to the substrate (open symbols). The references with no sugar addition are depicted with solid symbols. The final degree of conversion is indicated for each experiment.

and thus their collision rate, the inhibitor-to-enzyme level can determine the degree of inhibition. Xiao and co-workers showed that in hydrolysis of a cellobiose solution, addition of 20,50 and $100 \mathrm{~g} / \mathrm{l}$ of glucose to 2, 5 and $10 \%$ cellobiose $(\mathrm{w} / \mathrm{v})$ resulted in $\beta$-glucosidase inhibition of 53,51 and $48 \%$, respectively. The almost identical degree of inhibition at different sugar concentrations shows that the inhibitor-to-enzyme ratio is essential in product inhibition [32]. Based on this, it does not appear likely that inhibition of $\beta$-glucosidase is the main cause of the solids effect. However, indirectly the cellobiohydrolases are even stronger inhibited by glucose. The high glucose concentration inhibits $\beta$-glucosidase, which in turn leads to an accumulation of cellobiose, which acts as a particularly strong inhibitor of cellobiohydrolases [33].

Surprisingly, cellobiose concentrations in our experiments have generally been low. Normally, even at high solids concentrations and $80 \%$ conversion, less than $10 \%$ of the converted material is found as cellobiose (data not shown). For comparison, during experiments with lower proportions of $\beta$-glucosidase, inhibition caused cellobiose proportions of over $35 \%$ of the converted material while still retaining a certain degree of hydrolysis (data not shown).

SSF is normally used to offset the well-known effects of glucose and cellobiose inhibition but interestingly the solids effect has also been observed under those conditions $[12,17,19]$. Ethanol is also known to act as an inhibitor of cellulases (although less severe an inhibitor than cellobiose) $[31,45]$, indicating that other factors may influence the conversion under these conditions.

To test if product inhibition was the sole cause of the solids effect a new experiment was carried out. Filter paper was hydrolysed using three different combinations of enzyme loading and time: 20 FPU (g DM)-1 for $22 \mathrm{~h}, 10$ FPU (g DM)-1 for $48 \mathrm{~h}$ and 5 FPU (g DM)-1 for $84 \mathrm{~h}$. This was done in order to reach approximately the same degree of conversion (45\%) despite using different enzyme loadings. This means that the same amount of sugar was released in all three experiments. Theoretically this amount of sugar should cause a larger degree of inhibition on a small amount of enzyme (low enzyme dosage but longer hydrolysis time) versus a larger amount of enzyme (high enzyme dosage but short hydrolysis time) as per the 
inhibitor-to-enzyme ratio previously discussed. As seen in Figure 4 , the slopes of the three curves are nearly identical. If product inhibition alone was the cause, one would expect the hydrolysis with the lowest enzyme-to-substrate ratio (that is, lowest enzyme dosage) to display the strongest degree of inhibition and thus a steeper curve. In other words, it is not possible to bypass the solids effect by using higher enzyme dosages, at least not within the normal range of dosages. This is an important consideration when trying to alleviate the solids effect.

In conclusion, product inhibition at increased solids concentrations was found to be a significant and potentially determining factor for the solids effect. However, the linearity over a large range of solids contents of our experiments does not fit with the current models for product inhibition.

\section{Water concentration}

Oleyl alcohol has previously been shown to exhibit partitioning behaviour towards water and sugars [39] and our experiments showed no detrimental effects on enzyme performance (data not shown). Therefore, it was possible to use oleyl alcohol to replace water in order to investigate the water-to-enzyme/solids ratio while keeping the viscosity similar. The reasoning behind these experiments is that by substituting part of the water, it is possible to run a hydrolysis with an altered water-to-enzyme ratio but with

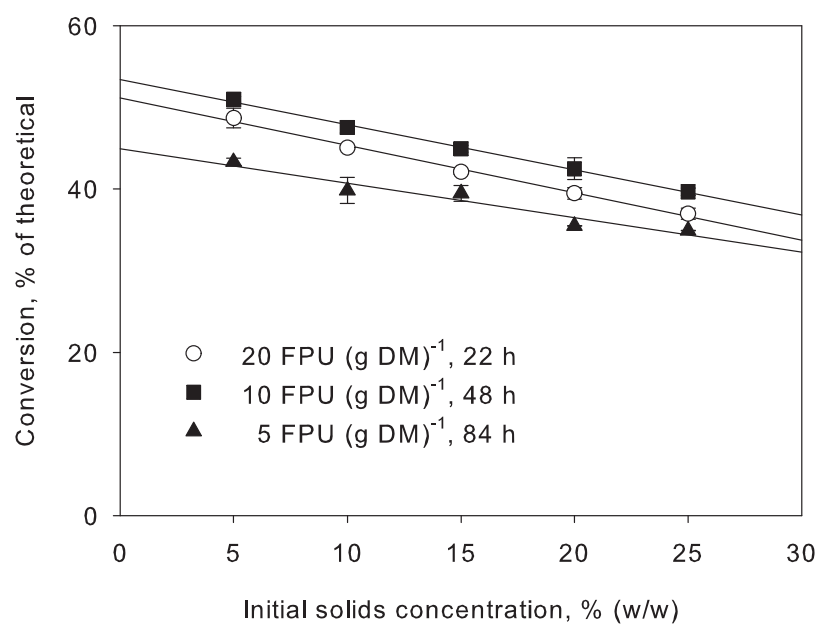

Figure 4

Enzyme loadings. Filter paper was hydrolysed at small laboratory scale to approximately the same extent by using three different enzyme loadings and lengths of hydrolysis time: $20 \mathrm{FPU}$ per gram dry matter (DM), for $22 \mathrm{~h}, 10 \mathrm{FPU}$ per gram dry matter, for $48 \mathrm{~h}$ and 5 FPU per gram dry matter for $84 \mathrm{~h}$. Points are averages of three observations. No significant difference in slope of the curves at the different enzyme loadings was observed. a more-or-less constant viscosity of the slurry. If a lack of water is causing the solids effect, then the hydrolysis conversion where a certain amount of the water has been replaced should be lower, presumably at the level of the corresponding solids level (taking only the aqueous phase in consideration).

In Figure 5, a quarter of the water (buffer) in an enzymatic hydrolysis of $20 \%$ solids filter paper has been substituted. At this level of substitution, the actual solids concentration in relation to water has therefore been increased from 20 to $25 \%$. After $40 \mathrm{~h}$ of hydrolysis, $5.6 \%$ less glucose compared with the reference (without oleyl alcohol addition) was released. However, the increase from 20 to $25 \%$ solids usually leads to a decrease in conversion of over $12 \%$. Thus, the decrease in conversion did not correspond directly to the lowered water content.

However, the sugar concentration is not the only parameter that has been changed. Oleyl alcohol may act as a mixing agent, fully or partially replacing the effect of water in assisting mass transfer, even if neither enzymes nor sugars can be solubilised in oleyl alcohol. As previously discussed, the interconnection of factors affecting the yield is characteristic of lignocellulose hydrolysis, complicating the identification of limiting factors.

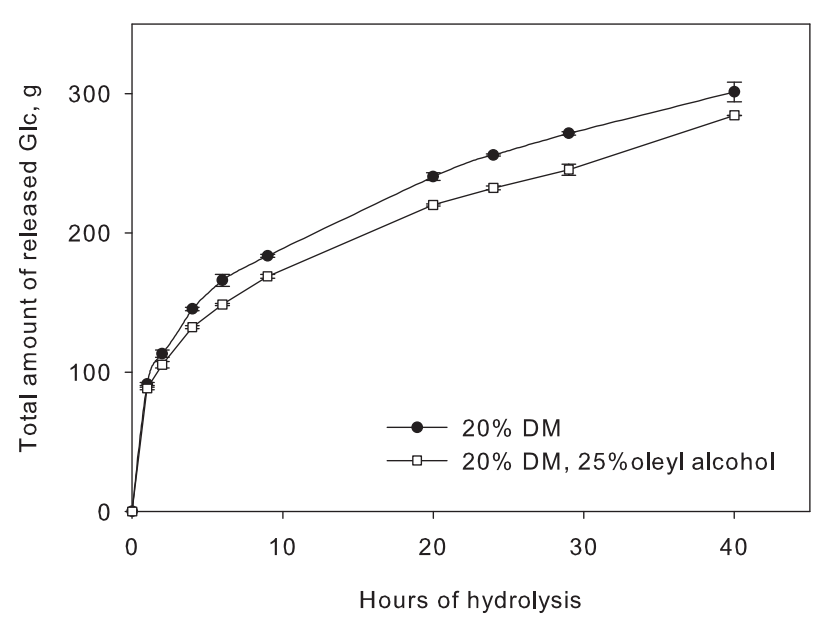

Figure 5

Replacement of water. Hydrolysis of filter paper at large laboratory scale with $20 \%$ initial solids content (w/w) and an enzyme dosage of 10 FPU per gram dry matter (DM) where $25 \%$ of the water was replaced with the inert oil, oleyl alcohol. This corresponds to an increase of biomass to water ratio of $25 \%$. The yield was found to be less than the reference, but not as low as a $25 \%$ increase in solids normally results in. Points are averages of two experiments. 
There is no doubt that water plays a number of important roles in enzymatic hydrolysis, and that these roles become even more crucial in systems with no free water. As cellulases can only break down cellulose when adsorbed onto the material, efficient mass transfer of enzymes is likely to increase conversion. Also, diffusion of released sugars away from the catalytic sites will theoretically prevent local product inhibition. Mechanical stirring may also directly change the size distribution of larger particles. Unfortunately, our understanding of these mechanistic interactions is limited and also depends on the cell wall structure of the substrate. It is likely that such factors affect the degree of conversion at very high solids loadings, essentially causing a drop-off in yield over a certain solids loading. However, as already discussed, the observed solids effect is also seen at loadings as low as 2 to $5 \%$ solids and thus mass transfer at neither the macroscopic nor the molecular level appears be responsible for the solids effect.

Related to the diffusion of enzymes is the phenomenon of substrate inhibition, which has previously been described in connection with hydrolysis of cellulose [46]. At increased substrate concentrations, with a fixed enzyme loading, the lateral (two-dimensional) diffusion of bound enzymes is believed to be restricted, thus inhibiting the synergy between exo and endo-enzymes [47]. However, this form of synergistic inhibition relates to a fixed enzyme load where the amount of substrate is increased, that is, a decreasing enzyme-substrate ratio as opposed to a constant ratio as used in our and other's experiments. Therefore, this phenomenon is not likely to be involved in the solids effect. Traditionally, substrate inhibition is explained as a situation where two molecules of substrate bind to the enzyme simultaneously, thereby blocking activity. However, this mechanism is not likely to be applicable to the hydrolysis of cellulose due to its insoluble nature [48].

In conclusion, water itself as a substrate or diffusing agent in enzymatic hydrolysis does not appear to be the limiting factor responsible for the solids effect, nor is substrate inhibition involved.

\section{Adsorption}

Based on previous reports on inhibition of enzyme adsorption, it was investigated if the increased sugar concentration at high solids concentration could cause the solids effect in this manner $[42,43]$. As seen in Figure 6, there is a linear correlation between initial solids content and amount of adsorbed enzyme (percentage of nitrogen adsorbed on solids of total nitrogen added). After $24 \mathrm{~h}$ of hydrolysis of $5 \%$ solids filter paper, approximately $40 \%$ of the added enzyme was adsorbed onto the remaining solids. The adsorption decreases with increasing solids con- tent, and at $30 \%$ solids content only approximately $17 \%$ of the added enzyme is adsorbed, despite significantly more solids remaining than at lower solids contents. Even more interestingly, linear regression of sample pairs reveals a statistically significant correlation between the decrease in conversion and the decrease in enzyme adsorption. In other words, it appears that the increasing concentrations of glucose and cellobiose in high-solids hydrolysis result in inhibition of adsorption of the enzymes. As adsorption is a requirement for hydrolysis of the insoluble substrate, this in return results in lower conversion at increasing solids concentrations.

Based on an experiment with a fixed cellobiose concentration, Kumar and Wyman argue that binding inhibition can be reversed using high substrate concentrations [43]. However, working with a fixed inhibitor concentration over a range of solids concentrations does not reflect the actual conditions since high solids loadings will invariably lead to higher product concentrations. At any degree of conversion, the ratio between substrate and inhibitor (product) in hydrolysis will be constant no matter the initial solids concentration. Xiao and co-workers also observed reduced impact of products on inhibition at higher solids loadings, but again it was measured against a constant inhibitor concentration [32]. Based on our experiments we do not believe that increased solids con-

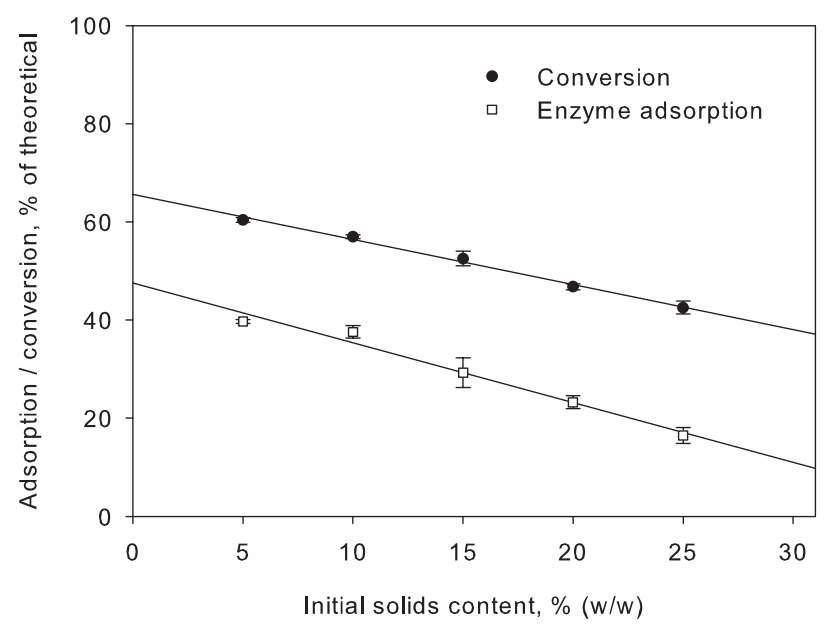

\section{Figure 6}

Enzyme adsorption. Upper graph shows the decreasing conversion in enzymatic conversion of filter paper at increasing solids loading (20 FPU per gram dry matter (DM), $24 \mathrm{~h}$ hydrolysis at small laboratory scale). Points are averages of three observations. The lower graph shows the adsorption of enzyme on the solid fraction based on total nitrogen content, also as a function of initial solids content. Values are averages of three observations and have been corrected for varying amounts of remaining solids. 
centrations can reverse binding inhibition, rather the opposite.

It can be argued that the phenomenon described above is a variant of product inhibition. In both competitive and non-competitive inhibition the catalytic site is affected, which is not necessarily the case with inhibition of adsorption. Although $\beta$-glucosidase does not bind to the substrate and thus is not affected in this way, the binding inhibition of endoglucanases and cellobiohydrolases can possibly explain the low cellobiose levels under conditions where hydrolysis is inhibited.

It is not known to what extent inhibition of adsorption is responsible for the solids effect, or if it can be partially avoided through SSF. It has previously been shown that adsorption inhibition could not explain the decrease in cellulase activity [49]. In an attempt to learn more about the nature of the inhibition, we used the data of the experiment in Figure 2 to investigate the relationship between the rate of reaction and glucose concentration. We found no direct relationship (data not shown), possibly due to the fact that different proportions of the substrate remained, that is, when $50 \%$ of the substrate has been converted, the remainder is more difficult to hydrolyse.

It is likely that the cellulose binding domains (CBD) of the cellulases are affected by glucose and cellobiose. Binding of cellulases and clarification of the role of CBDs is an important topic in cellulosic biomass conversion, and has been the topic of numerous studies. Being able to alter the CBD to make it less susceptible to a high concentration of products may contribute to making high yields at high solids concentrations a reality.

\section{Conclusion}

The extent of enzymatic conversion of cellulosic biomass was investigated at varying solids concentrations. The conversion decreased at increasing solids concentration in a linear fashion, an effect that appears to be a generic or intrinsic feature of lignocellulose conversion. This decrease partially offsets the significant advantages of working at high solids concentrations. The solids effect did not appear to be caused by lignin content or hemicellulose-derived inhibitors. Lack of mixing of the insoluble substrate did not appear to be causing the effect either.

The increased concentration of glucose and cellobiose at high solids concentration are likely to cause product inhibition even when the enzyme-to-inhibitor ratio is constant. However, the solids effect has also been observed in SSF where much less sugar is present.

It was found that at increasing solids concentrations, the proportion of adsorbed cellulase decreased. There was a statistically significant correlation between this adsorption inhibition and the decreasing yields at increasing substrate concentrations. Thus, the solids effect may well be explained by inhibition of the binding of the cellulases. The exact extent and mechanism of the adsorption inhibition is still unknown. It is possible that improvement of cellulase CBDs may lead to enzymes that are more resistant to high sugar concentrations and thus higher conversions at high solids concentrations, significantly improving the viability of lignocellulosic biomass conversion.

\section{Methods}

\section{Compositional analysis}

The composition of filter paper (AGF $725,140 \mathrm{~g} / \mathrm{m}^{2}$ from Frisenette ApS, Knebel, Denmark) was analysed using two-step acid hydrolysis according to the procedure published by NREL [50]. Dry matter content was determined using a Sartorius MA 30 moisture analyser at $105^{\circ} \mathrm{C}$. The released sugars were quantified by high performance liquid chromatography (HPLC) as described below. The filter paper was found to consist of $80.6 \%$ glucan, $0.42 \%$ Klason lignin, $14.4 \%$ mannan, $1.0 \%$ arabinan, and $0.24 \%$ ash.

\section{Enzymatic hydrolysis}

The hydrolyses were performed using an enzyme mixture of Celluclast $1.5 \mathrm{~L}$ and Novozym 188 (weight ratio 5:1, both from Novozymes A/S, Bagsværd, Denmark) with a filter paper activity of 75 FPU per gram of dry matter (DM), as measured by the filter paper assay [51]. Enzyme loadings of 5 to 20 FPU per gram of DM and a hydrolysis times from 24 to $84 \mathrm{~h}$ were used. Hydrolysis temperature was $50 \pm 1{ }^{\circ} \mathrm{C}$. Initial total solids content ranged from 5 to $35 \%(\mathrm{w} / \mathrm{w})$ and $\mathrm{pH}$ was kept constant by adding sodium citrate buffer (pH 4.80, $50 \mathrm{mM}$ final concentration).

Hydrolysis experiments were performed at one of two scales. The 'large' scale hydrolyses were done in a horizontal, five-chambered liquefaction reactor where each chamber is $20 \mathrm{~cm}$ wide and $60 \mathrm{~cm}$ in diameter as described in [4]. In this reactor, a total reaction mass (solids and liquids) of $5 \mathrm{~kg}$ was used. The rotational speed was approximately $6 \mathrm{rpm}$.

The 'small' scale hydrolysis was performed in $100 \mathrm{ml}$ plastic bottles (total reaction mass $50 \mathrm{~g}$ ), also at 5 to $25 \%$ solids content $(\mathrm{w} / \mathrm{w})$; buffer concentration and enzyme loadings as described above. The bottles were placed in a heated, horizontally placed drum, rotating at $60 \mathrm{rpm}$. The $80 \mathrm{~cm}$ diameter drum was equipped with two inside paddles that lifted and dropped the plastic bottles during rotation, mimicking the gravimetric mixing described in $[4,20]$. All small-scale experiments were performed in either duplicate or triplicate. 
Samples for HPLC sugar analysis were boiled for $10 \mathrm{~min}$ to terminate the reaction. Whole slurry was sampled after vigorous shaking to ensure a representable mixture of solids and liquid. Samples were then diluted five to tenfold with eluent before insoluble material was removed by centrifugation at $4,200 \times \mathrm{g}$ for $10 \mathrm{~min}$. The dilution factor was determined by measuring the weight of the sample before and after dilution. When working at high insoluble solids concentrations there is an increasing difference between the concentration in the liquid phase and the overall concentration of a component [7]. The dilution step minimises the measurement error introduced by the content of insoluble material, which would otherwise result in an overestimation when calculating the conversion, as discussed in [44].

\section{Sugar analysis}

The content of monosaccharides in the hydrolysed samples (D-glucose, D-xylose, L-arabinose and D-cellobiose) was quantified on a Dionex Summit HPLC system equipped with a Shimadzu RI-detector. The separation was performed in a Phenomenex Rezex RHM column at $80^{\circ} \mathrm{C}$ with $5 \mathrm{mM} \mathrm{H}_{2} \mathrm{SO}_{4}$ as eluent at a flow rate of $0.6 \mathrm{ml}$ $\mathrm{min}^{-1}$. Samples were filtered through a $0.45 \mu \mathrm{m}$ filter and diluted with eluent before analysis on HPLC.

\section{Inhibition experiments}

Before hydrolysis, various amounts of D-glucose (SigmaAldrich, Brøndby, Denmark) were added to the substrate. Conditions were as described above.

\section{Water replacement experiments}

Hydrolysis was run at 'large' scale, as described above, with $20 \%$ solids content $(\mathrm{w} / \mathrm{w})$ and an enzyme loading of 10 FPU (g DM) $)^{-1}$. Twenty-five per cent $(w / w)$ of the initial aqueous phase was substituted with oleyl alcohol. It was found that neither the enzyme nor the released sugars was present in the oleyl alcohol. Sugar concentration was measured in the aqueous phase only.

\section{Adsorption experiments}

For cellulase adsorption studies, samples were kept on ice after hydrolysis instead of boiling, in order to prevent any desorption of enzyme from the solids. Rather than estimating the adsorption indirectly with a colorimetric method, total nitrogen content of the biomass was determined on an elemental analyser coupled to an isotope ratio mass spectrometer (ANCA SL \& 20-20, Europa Scientific, Crewe, UK). This method of measuring enzyme adsorption has recently been described by Kumar and Wyman [43]. As the cellulase mixture of Celluclast $1.5 \mathrm{~L}$ and Novozym 188 contains a proportion of non-binding enzymes, enzyme adsorption will never reach $100 \%$ of the added amount. To be able to subtract the nitrogen content of the liquid of the spun-down samples, the nitrogen con- tent of the aqueous phase was measured with the Kjeldahl method.

\section{Competing interests}

The authors declare that they have no competing interests.

\section{Authors' contributions}

JBK carried out the majority of the experiments and drafted the manuscript. CF participated in the inhibition work as well as design and coordination of the study. HJ participated in the general hydrolysis work as well as the experimental design and helped draft the manuscript. All authors suggested modifications to the draft, commented on several preliminary versions of the text and approved the final manuscript.

\section{Acknowledgements}

The project is financially supported by the Danish Research Agency contract 2104-05-0008.

\section{References}

I. Gray KA, Zhao L, Emptage M: Bioethanol. Curr Opin Chem Biol 2006, I0:14I-I46.

2. Jørgensen $H$, Kristensen JB, Felby $C$ : Enzymatic conversion of lignocellulose into fermentable sugars: challenges and opportunities. Biofpr 2007, I:I I9-134.

3. Himmel ME, Ding SY, Johnson DK, Adney WS, Nimlos MR, Brady JW, Foust TD: Biomass recalcitrance: Engineering plants and enzymes for biofuels production. Science 2007, 315:804-807.

4. Jørgensen $\mathrm{H}$, Vibe-Pedersen J, Larsen J, Felby C: Liquefaction of lignocellulose at high solids concentrations. Biotechnol Bioeng 2007, 96:862-870.

5. Pimenova NV, Hanley AR: Effect of corn stover concentration on rheological characteristics. Appl Biochem Biotechnol 2004, II 3-16:347-360.

6. Felby C, Thygesen LG, Kristensen JB, Jørgensen H, Elder T: Cellulose-water interactions during enzymatic hydrolysis as studied by time domain NMR. Cellulose 2008, I 5:703-710.

7. Hodge DB, Karim MN, Schell DJ, McMillan JD: Model-Based FedBatch for High-Solids Enzymatic Cellulose Hydrolysis. Appl Biochem Biotechnol 2009, I 52:88-107.

8. Wingren A, Galbe M, Zacchi G: Techno-economic evaluation of producing ethanol from softwood: Comparison of SSF and SHF and identification of bottlenecks. Biotechnol Prog 2003, 19:1 109-1 II 7.

9. Katzen R, Madson PW, Moon GD: Alcohol destillation - the fundamentals. In The Alcohol Textbook Edited by: Jacques KA, Lyons TP, Kelsall DR. Nottingham: Nottingham University Press; 1999: 103-1 25.

10. Zacchi G, Axelsson A: Economic-Evaluation of Preconcentration in Production of Ethanol from Dilute Sugar Solutions. Biotechnol Bioeng 1989, 34:223-233.

II. Fan ZL, South C, Lyford K, Munsie J, van Walsum P, Lynd LR: Conversion of paper sludge to ethanol in a semicontinuous solids-fed reactor. Bioprocess Biosyst Eng 2003, 26:93-101.

12. Mohagheghi A, Tucker M, Grohmann K, Wyman C: High Solids Simultaneous Saccharification and Fermentation of Pretreated Wheat Straw to Ethanol. Appl Biochem Biotechnol 1992, 33:67-8I.

13. Mandels M, Reese ET: Inhibition of Cellulases. Annu Rev Phytopathol 1965, 3:85-102.

14. Rosgaard L, Andric P, Dam-Johansen K, Pedersen S, Meyer AS: Effects of substrate loading on enzymatic hydrolysis and viscosity of pretreated barley straw. Appl Biochem Biotechnol 2007, 143:27-40.

15. Tolan JS: logen's process for producing ethanol from cellulosic biomass. Clean Technol Environ Policy 2002, 3:339-345.

16. Cara C, Moya M, Ballesteros I, Negro MJ, Gonzalez A, Ruiz E: Influence of solid loading on enzymatic hydrolysis of steam 
exploded or liquid hot water pretreated olive tree biomass. Process Biochem 2007, 42:1003-1009.

17. Varga E, Klinke HB, Reczey K, Thomsen AB: High solid simultaneous saccharification and fermentation of wet oxidized corn stover to ethanol. Biotechnol Bioeng 2004, 88:567-574.

18. Ballesteros M, Oliva JM, Manzanares P, Negro MJ, Ballesteros I: Ethanol production from paper material using a simultaneous saccharification and fermentation system in a fed-batch basis. World J Microbiol Biotechnol 2002, 18:559-56I.

19. Thomsen MH, Thygesen A, Jørgensen H, Larsen J, Christensen BH, Thomsen $A B$ : Preliminary results on optimisation of pilot scale pre-treatment of wheat straw used in co-production of bioethanol and electricity. Appl Biochem Biotechnol 2006, I29132:448-460.

20. Larsen J, Petersen M $\varnothing$, Thirup L, Li HW, Iversen FK: The IBUS process - Lignocellulosic Bioethanol Close to a Commercial Reality. Chem Eng Technol 2008, 3 I:765-772.

21. Ingesson H, Zacchi G, Yang B, Esteghlalian AR, Saddler JN: The effect of shaking regime on the rate and extent of enzymatic hydrolysis of cellulose. J Biotechnol 200I, 88: 177-I82.

22. Lu YP, Yang B, Gregg D, Saddler JN, Mansfield SD: Cellulase adsorption and an evaluation of enzyme recycle during hydrolysis of steam-exploded softwood residues. Appl Biochem Biotechnol 2002, 98:64I-654.

23. Schwald W, Breuil C, Brownell HH, Chan M, Saddler JN: Assessment of Pretreatment Conditions to Obtain Fast Complete Hydrolysis on High Substrate Concentrations. Appl Biochem Biotechnol 1989, 20-I:29-44.

24. Tengborg C, Galbe M, Zacchi G: Influence of enzyme loading and physical parameters on the enzymatic hydrolysis of steampretreated softwood. Biotechnol Prog 2001, 17:110-117.

25. Hodge DB, Karim MN, Schell DJ, McMillan JD: Soluble and insoluble solids contributions to high-solids enzymatic hydrolysis of lignocellulose. Bioresour Technol 2008, 99:8940-8948.

26. Panagiotou G, Olsson L: Effect of compounds released during pretreatment of wheat straw on microbial growth and enzymatic hydrolysis rates. Biotechnol Bioeng 2007, 96:250-258.

27. Pan XJ: Role of functional groups in lignin inhibition of enzymatic hydrolysis of cellulose to glucose. J Biobased Mater Bioenergy 2008, 2:25-32.

28. Sørensen I, Pedersen S, Meyer AS: Optimization of reaction conditions for enzymatic viscosity reduction and hydrolysis of wheat arabinoxylan in an industrial ethanol fermentation residue. Biotechnol Prog 2006, 22:505-5I3.

29. Rosgaard L, Pedersen S, Cherry JR, Harris P, Meyer AS: Efficiency of new fungal cellulase systems in boosting enzymatic degradation of barley straw lignocellulose. Biotechnol Prog 2006, 22:493-498.

30. Georgieva TI, Hou XR, Hilstrom T, Ahring BK: Enzymatic hydrolysis and ethanol fermentation of high dry matter wetexploded wheat straw at low enzyme loading. Appl Biochem Biotechnol 2008, 148:35-44.

31. Bezerra RMF, Dias AA: Enzymatic kinetic of cellulose hydrolysis - Inhibition by ethanol and cellobiose. Appl Biochem Biotechnol 2005, I 26:49-59.

32. Xiao ZZ, Zhang X, Gregg DJ, Saddler JN: Effects of sugar inhibition on cellulases and beta-glucosidase during enzymatic hydrolysis of softwood substrates. Appl Biochem Biotechnol 2004, II3-16: III5-1126.

33. Gruno M, Valjamae P, Pettersson G, Johansson G: Inhibition of the Trichoderma reesei cellulases by cellobiose is strongly dependent on the nature of the substrate. Biotechnol Bioeng 2004, 86:503-5II.

34. Holtzapple M, Cognata M, Shu Y, Hendrickson C: Inhibition of Trichoderma-Reesei Cellulase by Sugars and Solvents. Biotechnol Bioeng 1990, 36:275-287.

35. Zhang S, Wolfgang DE, Wilson DB: Substrate heterogeneity causes the nonlinear kinetics of insoluble cellulose hydrolysis. Biotechnol Bioeng 1999, 66:35-41.

36. Väljamäe P, Kipper K, Pettersson G, Johansson G: Synergistic cellulose hydrolysis can be described in terms of fractal-like kinetics. Biotechnol Bioeng 2003, 84:254-257.

37. Zaccai G: The effect of water on protein dynamics. Philos Trans $R$ Soc Lond B Biol Sci 2004, 359: 1269-1275.

38. Bruce LJ, Daugulis AJ: Solvent selection-strategies for extractive biocatalysis. Biotechnol Prog 1991, 7:। 16-124.
39. Moritz JW, Duff SJB: Simultaneous saccharification and extractive fermentation of cellulosic substrates. Biotechnol Bioeng 1996, 49:504-5II.

40. Jeoh T, Ishizawa Cl, Davis MF, Himmel ME, Adney WS, Johnson DK Cellulase digestibility of pretreated biomass is limited by cellulose accessibility. Biotechnol Bioeng 2007, 98: I I 2-I 22

4I. Tanaka M, Nakamura H, Taniguchi M, Morita T, Matsuno R, Kamikubo $\mathrm{T}$ : Elucidation of Adsorption Processes of Cellulases During Hydrolysis of Crystalline Cellulose. Appl Microbiol Biotechnol 1986, 23:263-268.

42. Stutzenberger F, Lintz G: Hydrolysis Products Inhibit Adsorption of Trichoderma-Reesei C30 Cellulases to ProteinExtracted Lucerne Fibers. Enzyme Microb Technol 1986, 8:34I-344.

43. Kumar R, Wyman CE: An improved method to directly estimate cellulase adsorption on biomass solids. Enzyme Microb Technol 2008, 42:426-433.

44. Kristensen JB, Felby C, Jørgensen $\mathrm{H}$ : Determining yields in high solids enzymatic hydrolysis of biomass. Appl Biochem Biotechnol 2009, I 56: 127-32.

45. Ooshima $H$, Ishitani $Y$, Harano $Y$ : Simultaneous saccharification and fermentation of cellulose: Effect of ethanol on enzymatic saccharification of cellulose. Biotechnol Bioeng 1985, 27:389-397.

46. Väljamäe P, Pettersson G, Johansson G: Mechanism of substrate inhibition in cellulose synergistic degradation. Eur J Biochem 200I, 268:4520-4526.

47. Fenske JJ, Penner MH, Bolte JP: A simple individual-based model of insoluble polysaccharide hydrolysis: the potential for autosynergism with dual-activity glycosidases. J Theor Biol 1999 , 199:113-118.

48. Huang $\mathrm{XL}$, Penner MH: Apparent substrate inhibition of the Trichoderma reesei cellulase system. J Agric Food Chem 1991, 39:2096-2100.

49. Oh KK, Kim SW, Jeong YS, Hong SI: Bioconversion of cellulose into ethanol by nonisothermal simultaneous saccharification and fermentation. Appl Biochem Biotechnol 2000, 89:I5-30.

50. Sluiter $A$ : Determination of structural carbohydrates and lignin in biomass. NREL Laboratory Analytical Procedures. National Renewable Energy Laboratory, Golden, CO, USA; 2004.

5I. Wood T, Bhat KM: Methods for measuring cellulase activities. In Biomass - Part A: Cellulose and hemicellulose San Diego: Academic Press; 1988:87-II2.

Publish with Biomed Central and every scientist can read your work free of charge

"BioMed Central will be the most significant development for disseminating the results of biomedical research in our lifetime. "

Sir Paul Nurse, Cancer Research UK

Your research papers will be:

- available free of charge to the entire biomedical community

- peer reviewed and published immediately upon acceptance

- cited in PubMed and archived on PubMed Central

- yours - you keep the copyright
BioMedcentral 